\title{
Reply to: 'A late Pleistocene clockwise rotation phase of Zakynthos (Greece) and implications for the evolution of the western Aegean Arc'放
}

\author{
C.E. Duermeijer, C.G. Langereis* \\ Paleomagnetic Laboratory 'Fort Hoofddijk', Faculty of Earth Sciences, Utrecht University, Budapestlaan 17, 3584 CD Utrecht, \\ The Netherlands
}

Received 7 November 2000; received in revised form 15 January 2001; accepted 17 January 2001

During the $80 \mathrm{~s}$, a number of seminal papers were published by the Gif-sur-Yvette group of Carlo Laj and co-workers, on the late Neogene palaeomagnetic rotations of the Aegean and, in particular, of the Aegean Arc system. These studies shed new light on the tectonic evolution of the region (e.g. [1,2]). Then, similar work on the Calabrian-Sicilian arc system established that major tectonic rotations were of very young (middle Pleistocene) age [3], and it became clear to us that it was warranted to have a closer and more detailed look at the tectonic history of the Aegean Arc. In particular, the advent of more accurate, astronomically calibrated time scales during the 90s provided the opportunity to correlate tectonic (or other, e.g. climatic) events over a large geographical area, and to constrain their age and duration and hence their (a)synchrony. This would aid in testing a dynamical model of subduction-related geodynamics of the (central) Mediterranean area [4]. Many studies, e.g. on numerical modelling of stress patterns, tomography, vertical motions and depot centre migration, and on tectonostratigraphy, have aided in testing this

\footnotetext{
论 PII of original article S0012-821X(99)00226-5.

* Corresponding author. Tel.: +31-30-253-1668; Fax: +31-30-253-1677; E-mail: langer@geo.uu.nl
}

hypothesis (see [5] for references). Meanwhile, the accurate time control has provided increasing evidence for relatively short periods of rapid, pulsed tectonic rotations (see [5] for references and discussion). This is in contrast to a more continuous deformation over a longer time interval, as was earlier suggested by Laj et al. [1] for the western Aegean Arc.

In a recent paper, Duermeijer et al. [6] provided new palaeomagnetic results from the island of $\mathrm{Za}$ kynthos (Greece), and concluded that the rotation of this island is much more recent than previously considered by Laj et al. In her comment, Kissel contests the reliability of this conclusion in this paper on the basis of the originally submitted version she reviewed, and which included the results of the anisotropy of magnetic susceptibility (AMS). These results were, unfortunately, not published in the final version, in part because of EPSL length constraints but also because the other reviewers concluded that the AMS results did not add to the main result of the paper - the young rotation - and hence could be omitted. Since Kissel's comment is on unpublished data, we take the opportunity to provide these results here (Table 1, Fig. 1). We also include a comparison between AMS lineations (or $k_{\max }$ directions) and palaeomagnetic rotations (Fig. 2).

Kissel recognises that the NNW lineations 


\section{Pleistocene}
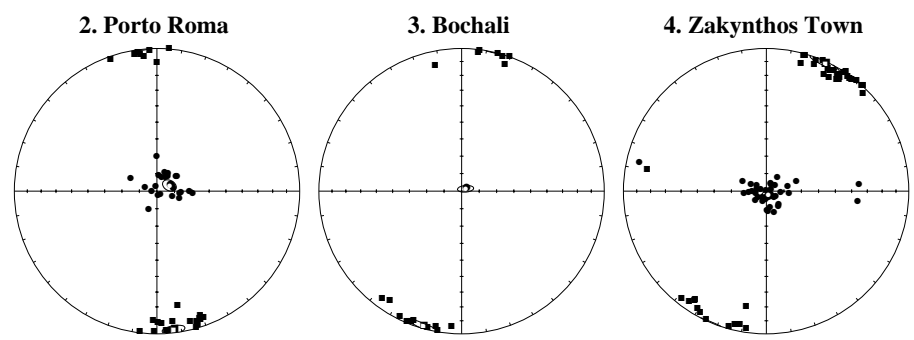

\section{Pliocene}
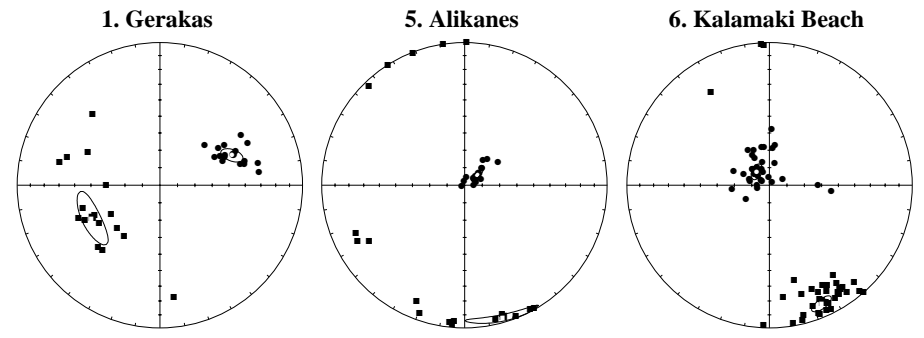

Miocene
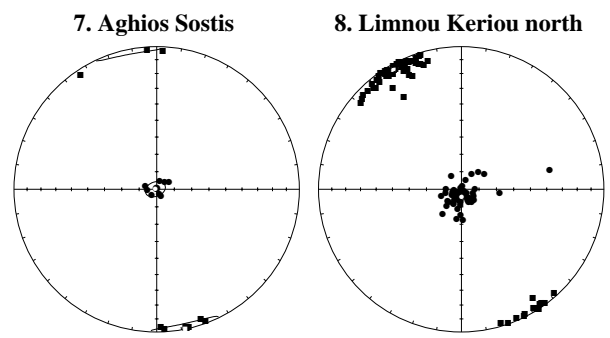

9. Limnou Keriou south
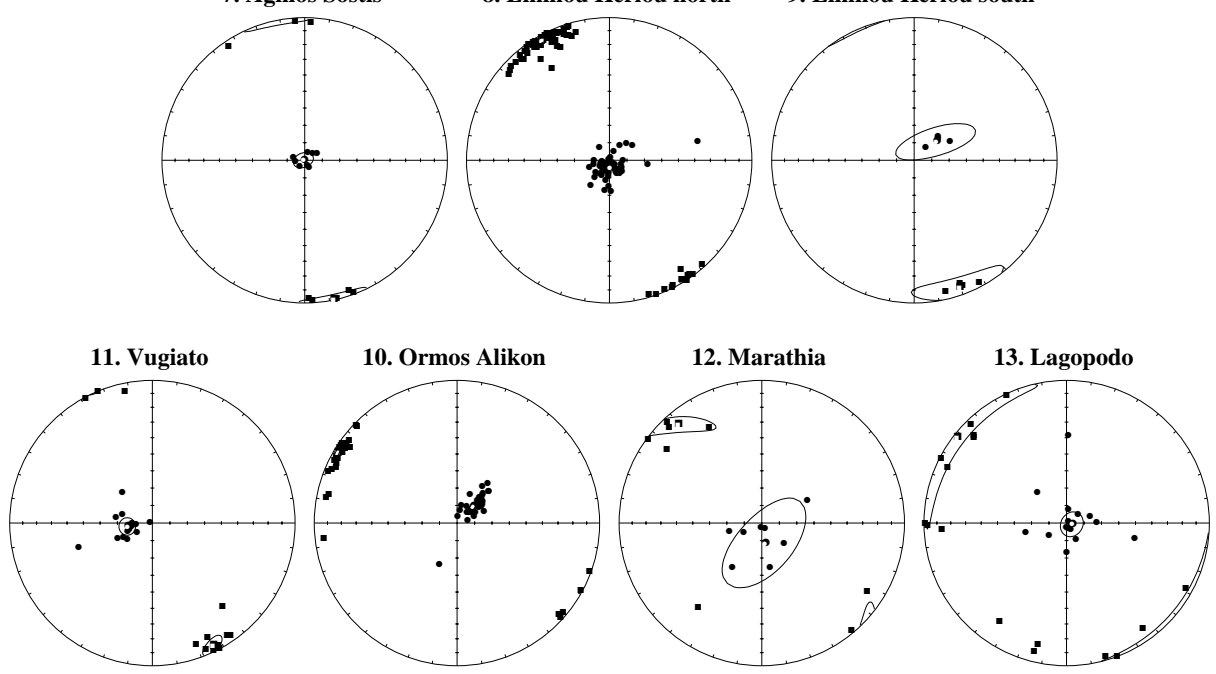

Fig. 1. Equal area plots of the directions of $k_{\max }$ (squares) and $k_{\min }$ (circles) for the sites from Zakynthos. In general, the AMS shows a mainly sedimentary fabric with $k_{\min }$ perpendicular to the bedding plane, except in Gerakas: the tectonic fabric is caused by diapirism and the site has been discarded as reliable. All other sites show a tectonic overprint as evidenced by the clustering of $k_{\max }$ directions (lineations). Numbers refer to numbers in Table 1 and Fig. 2.

found by us in Zakynthos are consistent with those found earlier [7], but with the exception of those observed at Bochali and Zakynthos town (Figs. 1 and 2) which are two of the three sites documenting the young rotation. She argues that this deviating lineation may likely indicate a local tectonic history, weakening the interpretation as regional rotation. Indeed, we agree that the Bochali and Zakynthos town lineations could very well be caused by local tectonics. However, fundamentally there is no simple relation between alignment of the $k_{\max }$ axes (the lineation) and 
Table 1

Main results of the AMS

\begin{tabular}{|c|c|c|c|c|c|c|c|c|c|}
\hline Site & & $N$ & $\begin{array}{l}D_{\mathrm{Kmax}} \\
\left(^{\circ}\right)\end{array}$ & $\begin{array}{l}I_{\mathrm{K} \max } \\
\left(^{\circ}\right)\end{array}$ & $\begin{array}{l}K_{\text {mean }} \\
\left(10^{6} \mathrm{SI}\right)\end{array}$ & $P$ & $F$ & $L$ & $\begin{array}{l}\text { Age } \\
(\mathrm{Ma})\end{array}$ \\
\hline 1 Gerakas & GER & 16 & $244 \pm 16$ & $46 \pm 6$ & 250 & 1.0393 & 1.0359 & 1.0033 & $1.8-1.61$ \\
\hline 2 Porto Roma & PR & 25 & $173 \pm 5$ & $2 \pm 3$ & 134 & 1.0244 & 1.0173 & 1.0070 & $1.03-0.77$ \\
\hline 3 Bochali & $\mathrm{BOC}$ & 18 & $196 \pm 7$ & $2 \pm 2$ & 153 & 1.0224 & 1.0175 & 1.0048 & $1.37-1.24$ \\
\hline 4 Zakynthos town & $\mathrm{ZT}$ & 40 & $25 \pm 7$ & $2 \pm 2$ & 194 & 1.0349 & 1.0264 & 1.0083 & $1.94-1.44$ \\
\hline 5 Alikanes & ALE & 18 & $164 \pm 16$ & $4 \pm 3$ & 144 & 1.0489 & 1.0462 & 1.0026 & $3.31-2.73$ \\
\hline 6 Kalamaki Beach & KLB & 36 & $156 \pm 6$ & $10 \pm 3$ & 110 & 1.0298 & 1.0233 & 1.0064 & $5.95-5.21$ \\
\hline 7 Aghios Sostis & SOS & 8 & $169 \pm 14$ & $0 \pm 4$ & 187 & 1.0530 & 1.0456 & 1.0071 & Messinian \\
\hline 8 Limnou Keriou (north) & $\mathrm{LMN}$ & 57 & $331 \pm 3$ & $4 \pm 2$ & 222 & 1.0442 & 1.0336 & 1.0103 & $7.24-6.60$ \\
\hline 9 Limnou Keriou (south) & LMS & 4 & $161 \pm 21$ & $6 \pm 8$ & 75 & 1.0316 & 1.0246 & 1.0068 & Tortonian \\
\hline 10 Ormos Alikon & ALO & 33 & $300 \pm 4$ & $3 \pm 1$ & 268 & 1.0644 & 1.0499 & 1.0138 & $7.64-7.24$ \\
\hline 11 Vugiato & VUG & 14 & $154 \pm 7$ & $5 \pm 4$ & 279 & 1.0307 & 1.0145 & 1.0160 & $8.11-7.70$ \\
\hline 12 Marathia & MA & 8 & $320 \pm 22$ & $10 \pm 5$ & 25 & 1.0317 & 1.0191 & 1.0124 & Serravallian \\
\hline 13 Lagopodo & LAG & 16 & $308 \pm 40$ & $3 \pm 6$ & 31 & 1.0143 & 1.0120 & 1.0023 & early middle Miocene \\
\hline 14 Lithakia & LIT & no data & & & & & & & early middle Miocene \\
\hline 15 Keri & $\mathrm{KE}$ & no data & & & & & & & Eocene \\
\hline
\end{tabular}

$N$ is the number of samples measured per site/locality; the declination $D$ and inclination $I$ of the maximum susceptibility axis $k_{\max }$ are given together with their error derived from the $\mathrm{e}_{12}$ error ellipse, as well as mean susceptibility $k_{\text {mean }}$, anisotropy degree $P$, foliation $F$ and lineation $L$.

the direction of the characteristic remanent magnetisation (ChRM); see for instance [8]. In the still predominantly sedimentary fabrics as found in Zakynthos, with $k_{\min }$ approximately perpendicular to the bedding plane (with the notable exception of Gerakas, Fig. 1 ; site 1 in Fig. 2) the $k_{\max }$ quickly aligns perpendicular to compressive strain, even in seemingly undeformed sediments (see $[8,9])$. Hence, all we may conclude is that the observed $k_{\max }$ directions document the compressive strain directions perpendicular to it (or, equivalently, extensional strain parallel to $k_{\max }$ ). A deviating strain direction may involve a rotation of the stress field, but does not - at low to moderate strain fields - produce a noticeable rotation of the ChRM [8]. Furthermore, in the monoclinal and slightly dipping Bochali and $\mathrm{Za}$ kynthos town sections we did not find any evidence for strong (multiphase) deformation, in contrast to Gerakas which indeed was omitted from the final results [6] even though the ChRM results - with a large error - were in line with the overall trend.

There are several well documented cases where there is a significant correlation between lineations and ChRM declinations, or palaeomagnetic rotations. For instance, in the Central Apennines
[10], the observed magnetic lineations have developed at an early stage of tectonic deformation, during a compressional phase. Subsequent differential rotations about a vertical axis caused, on average, similar and corresponding rotations of the lineations, implying that the original magnetic fabric has survived (was not overprinted by) the stress field related to the rotations. At the individual site or locality level, however, the deviation from the general trend between rotations of the ChRM and lineations of the AMS can be as large as $40^{\circ}$ [10]. In contrast to these studies, however, Scheepers and Langereis [11] found, in the Southern Apennines, clear evidence that magnetic lineations were more dispersed when corrected for rotations, and they argued that the development of the lineations occurred at a later stage, i.e. after the rotational phase.

Hence, the argument of Kissel that a deviating lineation may signify a local tectonic history is correct, but it may only signify that the magnetic fabric is determined by a younger (or older, for that matter) tectonic phase with a different direction. Furthermore, it can be seen that also the lineation found in the third Pleistocene site (Porto Roma, Fig. 2) is also clearly east of the consistent trend observed in the older sediments. In all three 


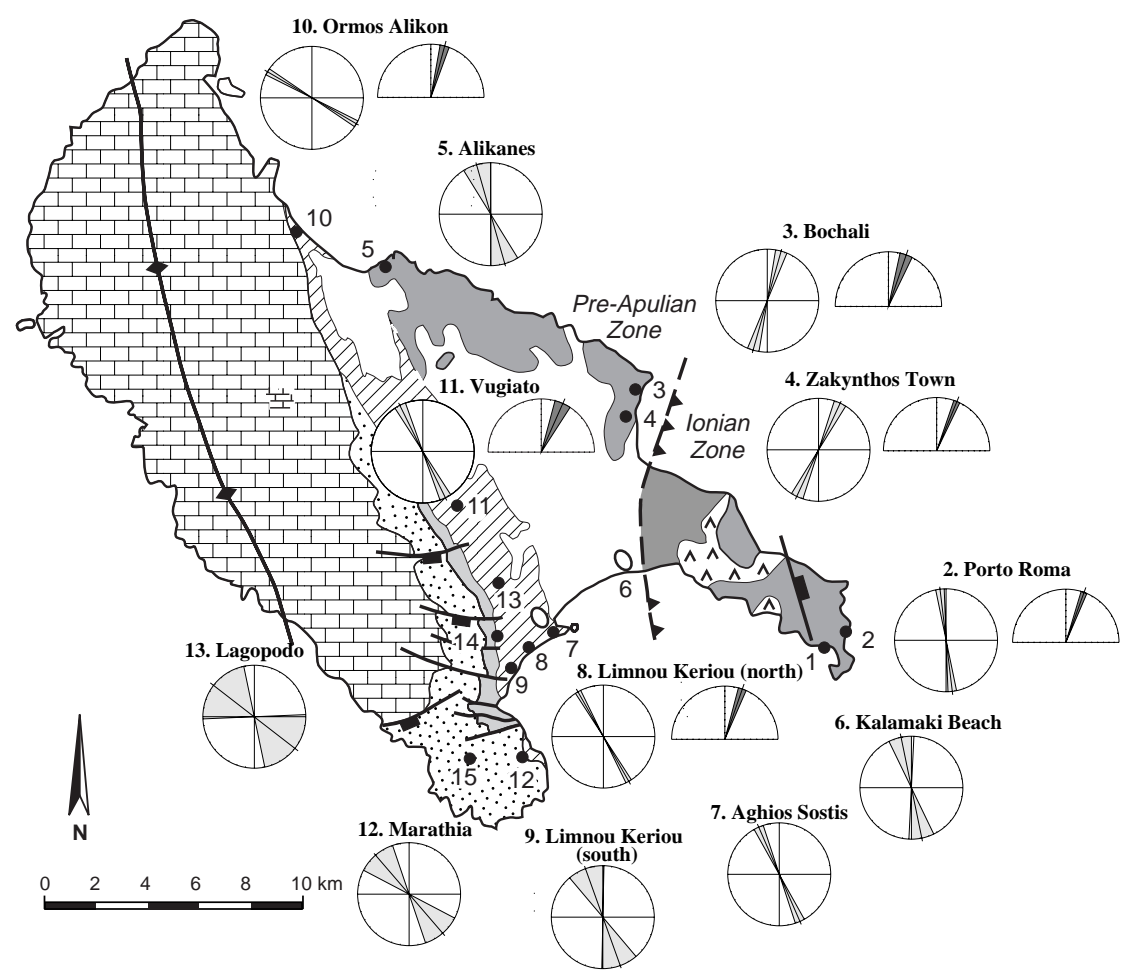

Fig. 2. Overview of the AMS lineations and their error (shaded) from Table 1 in circles, and the ChRM directions with their (shaded) error of $\alpha_{95} / \cos I$ in half-circles. The Ionian Thrust separates the Ionian and Pre-Apulian tectonic domains.

Pleistocene sites, therefore, the lineation seems parallel to the strike of the Ionian Thrust (Fig. 2 ), even though the exact location and direction of this thrust are subject to debate and not precisely known. Almost without exception, the lineations of the Pliocene and Miocene sites closely follow the regional structure, approximately parallel to the anticlinal axis (Fig. 2). However, considering the uncertainty of the exact position of the Ionian Thrust, we have earlier refrained from such speculation.

Here, we point out that the observed rotations from the five reliable sites on Zakynthos (Fig. 2) are consistently the same. The results of three other sites (1, 5 and 6 in Fig. 2) have been omitted because they were deemed unreliable, all other sites gave no reliable palaeomagnetic results [6]. The clockwise rotations on Zakynthos agree excellently with similarly young and consistent rotations from the NW Peloponnesus [5], even though here we found widely scattered and inconsistent lineations. But perhaps the most significant support for our conclusion is that these young rotations are in excellent agreement with rotation rates of $12-16 \% \mathrm{Myr}$ derived from inversion of the velocity field of present-day crustal deformation as observed from satellite geodesy [5]. Therefore, we see no reason to reject our earlier conclusion that the observed rotations are caused by a rapid and very young rotation phase.[R $\boldsymbol{V}]$

\section{References}

[1] C. Laj, J.M. Sorel, J.P. Valente, First paleomagnetic results from Mio-Pliocene series of the Hellenic sedimentary arc, Tectonophysics 86 (1982) 45-67.

[2] C. Kissel, C. Laj, The Tertiary geodynamical evolution of the Aegean Arc: a paleomagnetic reconstruction, Tectonophysics 146 (1988) 183-201.

[3] P.J.J. Scheepers, Tectonic rotations in the Tyrrhenian arc system during the Quaternary and late Tertiary, Ph.D. Thesis, Utrecht University, Geologica Ultraiectina 112, 1994, 352 pp. 
[4] M.J.R. Wortel, W. Spakman, Structure and dynamics of subducted lithosphere in the Mediterranean region, Proc. K. Ned. Akad. Wet. 95 (1992) 325-347.

[5] C.E. Duermeijer, M. Nyst, P.T. Meijer, C.G. Langereis, W. Spakman, Neogene evolution of the Aegean arc: paleomagnetic and geodetic evidence for a rapid and young rotation phase, Earth Planet. Sci. Lett. 176 (2000) 509525.

[6] C.E. Duermeijer, W. Krijgsman, C.G. Langereis, J.E. Meulenkamp, M.V. Triantaphyllou, W.J. Zachariasse, A late Pleistocene clockwise rotation phase of Zakynthos (Greece) and implications for the evolution of the western Aegean Arc, Earth Planet. Sci. Lett. 173 (1999) 315331.

[7] C. Kissel, E. Barrier, C. Laj, T.Q. Lee, Magnetic fabric in 'undeformed' marine clays from compressional zones, Tectonics 5 (1986) 769-781.

[8] F. Hrouda, Magnetic anisotropy of rocks and its application in geology and geophysics, Geophys. Surv. 5 (1982) 37-82.

[9] D.H. Tarling, F. Hrouda, The Magnetic Anisotropy of Rocks, Chapman and Hall, London, 1993, 217 pp.

[10] M. Mattei, C. Kissel, R. Funiciello, Paleomagnetic and structural evidence of Neogene block rotations in the central Apenines (Italy), J. Geophys. Res. 100 (1995) 17863 17883.

[11] P.J.J. Scheepers, C.G. Langereis, Magnetic fabric of Pleistocene clays from the Tyrrhenian arc: a magnetic lineation induced in the final stage of the middle Pleistocene compressive event, Tectonics 13 (1994) 1190-1200. 